\title{
A Systematic Review of Fetal Genes as Biomarkers of Cardiac Hypertrophy in Rodent Models of Diabetes
}

\author{
Emily J. Cox ${ }^{19}$, Susan A. Marsh ${ }^{2 * 9}$
}

1 Graduate Program in Pharmaceutical Sciences, College of Pharmacy, Washington State University, Spokane, Washington, United States of America, 2 Department of Experimental and Systems Pharmacology, College of Pharmacy, Washington State University, Spokane, Washington, United States of America

\begin{abstract}
Pathological cardiac hypertrophy activates a suite of genes called the fetal gene program (FGP). Pathological hypertrophy occurs in diabetic cardiomyopathy (DCM); therefore, the FGP is widely used as a biomarker of DCM in animal studies. However, it is unknown whether the FGP is a consistent marker of hypertrophy in rodent models of diabetes. Therefore, we analyzed this relationship in 94 systematically selected studies. Results showed that diabetes induced with cytotoxic glucose analogs such as streptozotocin was associated with decreased cardiac weight, but genetic or diet-induced models of diabetes were significantly more likely to show cardiac hypertrophy $(P<0.05)$. Animal strain, sex, age, and duration of diabetes did not moderate this effect. There were no correlations between the heart weight:body weight index and mRNA or protein levels of the fetal genes $\alpha$-myosin heavy chain $(\alpha-\mathrm{MHC})$ or $\beta-\mathrm{MHC}$, sarco/endoplasmic reticulum Ca ${ }^{2+}$-ATPase, atrial natriuretic peptide (ANP), or brain natriuretic peptide. The only correlates of non-indexed heart weight were the protein levels of $\alpha$-MHC (Spearman's $\rho=1, P<0.05)$ and ANP $(\rho=-0.73, P<0.05)$. These results indicate that most commonly measured genes in the FGP are confounded by diabetogenic methods, and are not associated with cardiac hypertrophy in rodent models of diabetes.
\end{abstract}

Citation: Cox EJ, Marsh SA (2014) A Systematic Review of Fetal Genes as Biomarkers of Cardiac Hypertrophy in Rodent Models of Diabetes. PLoS ONE 9(3): e92903. doi:10.1371/journal.pone.0092903

Editor: Sakthivel Sadayappan, Loyola University Chicago, United States of America

Received January 3, 2014; Accepted February 27, 2014; Published March 24, 2014

Copyright: (C) 2014 Cox, Marsh. This is an open-access article distributed under the terms of the Creative Commons Attribution License, which permits unrestricted use, distribution, and reproduction in any medium, provided the original author and source are credited.

Funding: This work was supported by grants from the National Institutes of Health (HL-104549) and the Diabetes Action Research and Education Foundation to SAM. EJC is supported by a National Science Foundation Graduate Research Fellowship. The funders had no role in study design, data collection and analysis, decision to publish, or preparation of the manuscript.

Competing Interests: The authors have declared that no competing interests exist.

*E-mail: susan.marsh@wsu.edu

9 These authors contributed equally to this work.

\section{Introduction}

Activation of the fetal gene program (FGP) in the adult heart occurs after cardiac insults and is ubiquitously used as a biomarker of cardiac hypertrophy [1,2]. Diabetic cardiomyopathy is partly characterized by ventricular hypertrophy [3,4]; therefore, the FGP is commonly used as an indicator of diabetic cardiomyopathy in rodent models of diabetes. However, many studies show that fetal genes are unchanged or downregulated in these animal models. For example, rodent models of diabetes show lower circulating serum levels [5-7], lower protein levels in cardiac tissue [8,9], and lower cardiac transcript levels [8-16] of two commonly measured fetal genes, atrial and brain natriuretic peptide (ANP and BNP). We have also shown previously that the presence of type 2 diabetes in mice blocks cardiac expression of ANP in response to hypertrophic stimuli [17]. Another measure of FGP activation in the adult heart is a decrease in the expression of $\alpha$ - relative to $\beta$ myosin heavy chain (MHC); however, it has been reported that this ratio is actually increased in type 2 diabetic $d b / d b$ mouse hearts, and that this increase depends on the duration of diabetes [12].

To our knowledge it has not been shown that fetal genes are consistent markers of cardiac hypertrophy in rodent models of diabetes. Therefore, this systematic review was performed to determine whether these animals show higher expression of fetal genes in the heart, and whether these genes correlate with cardiac weight. The results of this analysis show that most fetal genes do not correlate with cardiac hypertrophy in diabetic animals, and that methods of diabetogenicity significantly moderate the development of cardiac hypertrophy and the expression of fetal genes.

\section{Overview of fetal genes}

The following genes are some of the most commonly measured members of the FGP that are often used as indicators of cardiac hypertrophy.

Serca2. The sarcoplasmic reticulum $\mathrm{Ca}^{2+}$ ATPase 2 (Serca2) is responsible for re-uptake of calcium into the SR following contraction of the sarcomere, thus permitting muscle relaxation. Levels of Serca2 increase throughout fetal development of the mammalian myocardium and are maintained in adulthood [18]. A decrease in Serca2 expression is observed in the diabetic heart [19-21] and may underlie diastolic dysfunction in diabetic cardiomyopathy $[21,22]$. However, the mechanism that underlies Serca2 loss in heart disease is not understood.

Myofilament proteins. Myosin filaments in the heart function as complexes composed of $\alpha$ and $\beta$ subunits. The rodent heart expresses three forms of myosin: an $\alpha$-MHC form, which has the highest ATPase activity and contractile velocity; an $\alpha$ - and $\beta$ MHC form; and a $\beta$-MHC form, which has the lowest contractile capability [23]. During fetal development, $\alpha$-MHC replaces 
$\beta$-MHC as the dominant transcript in cardiac muscle [24], and this difference is maintained perinatally. Therefore, a decrease in the $\alpha$-MHC/ $\beta$-MHC ratio is used as a marker of fetal gene reactivation in rodent hearts and is associated with cardiac hypertrophy [25]. It should be noted that the regulation of myosins in the human heart is different; while $\alpha$-MHC predominates in non-failing adult rodent hearts, the adult human ventricle expresses approximately 95\% $\beta$-MHC [26-28].

Other non-myosin cytoskeletal proteins which are changed in the hypertrophied heart include actin and titin. Skeletal $\alpha$-actin is highly expressed in fetal hearts and is not expressed in the adult heart; instead, adult hearts express cardiac $\alpha$-actin [29]. Therefore, skeletal $\alpha$-actin is considered a member of the FGP and is used as a marker of hypertrophy, and is associated with cardiac dysfunction [30]. A similar switch is observed in the expression of titin isoforms: embryonic hearts express much higher levels of the N2BA isoform of titin, which is replaced by the shorter N2B titin isoform in the perinatal and adult heart [31]; therefore, expression of the long-form N2BA in the adult heart is used as a marker of pathological cardiac hypertrophy.

Peptide hormones. Atrial and brain natriuretic peptide (ANP and BNP) are small peptide hormones. The prohormone precursors of ANP and BNP are encoded by the $\mathcal{N} p p a$ and $\mathcal{N} p p b$ genes, respectively, and are some of the most commonly measured members of the fetal gene program. ANP expression is an early marker of cardiac commitment and is activated by the fetal cardiac transcription factors GATA4 and NKS2-5 [32]. In adult hearts, $\mathrm{ANP}$ and BNP are used as markers of heart failure because they are secreted in response to cardiac wall strain [33], although the mechanism of release is only just now being elucidated [34]. While they largely regulate natriuresis and reduce blood pressure, ANP and BNP also antagonize cardiac hypertrophy [35,36] and fibrosis [37], and stimulate lipolysis [38].

Transcription factors. A suite of transcription factors governs the formation of the fetal heart and is used to mark FGP upregulation in the adult heart. The GATA4 transcription factor is expressed at high levels in the fetal myocardium and drives the formation of the fetal heart. It is required for normal valvular development [39,40], activates a broad group of cardiacspecific genes including ANP [41] and $\alpha$-MHC [42], and is required for upregulation of $\beta-\mathrm{MHC}$ in pathological hypertrophy after trans-aortic constriction surgery [43].

The NK2 homeobox protein (NKX2-5/CSX) is one of the earliest markers of commitment to the cardiac lineage in embryonic mesoderm [44]. Its expression is confined to the heart, and is upregulated in fetal development and maintained in the postnatal and adult heart [45]. NKX2-5 expression requires GATA4 [44] and overexpression of these two genes in tandem drives commitment of mesenchymal stem cells to the cardiac lineage [46]. Recapitulation of NKX2-5 and associated transcription factors (GATA4, MEF2, and SP1) expression occurs in animal models of congestive heart failure [47], and is considered a marker of fetal gene reactivation.

Collaborating transcription factors that regulate fetal genes through interactions with GATA4 and CSX include MEF2 and Hand1/2. MEF2 governs a family of transcription factors that regulates fetal gene expression in the adult heart. Hand $1 / 2$ (eHand/dHand) are expressed at high levels in the fetal heart, and both Handl and Hand2 activate $\mathcal{N} p p a$, via physical associations with MEF2 [48] and NKX2.5 [49].

Although the relationship between fetal genes and pathological hypertrophy is well characterized [1,50-52], it is not known how these genes are affected by diabetes. Therefore, the purpose of this systematic review was to determine whether the expression of fetal genes is a consistent marker of cardiac hypertrophy in studies that use rodent models of diabetes. We found no correlations between fetal gene expression and the HW:BW index in rodent models of diabetes, and our results show that methods of inducing experimental diabetes significantly affect the expression of fetal genes in rodent hearts.

\section{Methods}

\section{Inputs}

Diabetogenics. The search terms for diabetogenic drugs and commonly used animal models of diabetes were generated from a review article [53]. Drug-induced diabetes is most commonly accomplished by injection of cytotoxic glucose analogs, i.e. streptozotocin (STZ) and alloxan, both of which are taken up by glucose transporter 2 into pancreatic $\beta$-cells [54]. The diabetogenic drugs that were included in the search parameters were STZ, alloxan, dithizone, or 8-hydroxyquinolone, but it should be noted that only the former two drugs returned results. STZ- and alloxan-induced models of diabetes were categorized as "drug," spontaneous/genetic models were categorized as "spontaneous," and diet- or diet/drug-induced models were categorized as "other" for our analyses.

Fetal genes. The inputs for the most commonly measured fetal genes were gathered from review articles $[1,51,52]$. Several of these transcription factors were included in the a priori article search, including NFAT, SRF, and the SMAD family, but these did not return any additional results when included with our other search parameters.

\section{Search}

A MeSH search using the previously described inputs (TABLE 1) was used to generate an a priori list of 135 articles in PubMed. Of the 136 articles returned by the search, 42 were excluded for containing inapplicable data and one was excluded for having been retracted (FIGURE 1). Therefore, 93 articles were included in this review (TABLE S1).

We categorized diabetogenic categories as follows: "druginduced" (STZ or alloxan), "spontaneous" genetic models, or "other." "Other" included diet-induced, or combination diet- and low-dose STZ-induced diabetes. Diabetic phenotype was coded as type 1 diabetes mellitus (T1DM) or type 2 (T2DM) based on whether the intervention produced primary insulin deficiency (e.g. STZ models of diabetes) or insulin resistance (e.g. hyperinsulinemic genetic models of diabetes).

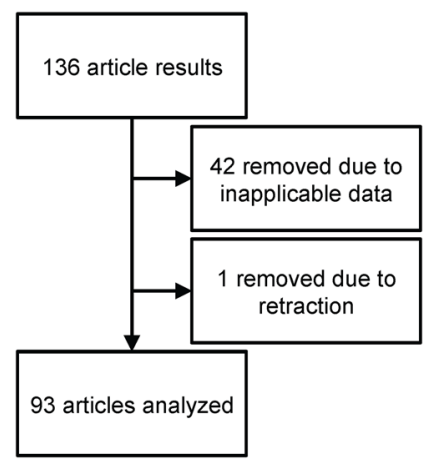

Figure 1. Flowchart of study selection. doi:10.1371/journal.pone.0092903.g001 
Table 1. Complete search terms used to collect articles from the PubMed database.

(cardiac[MeSH Major Topic] OR cardiac hypertrophy[MeSH Terms] OR cardiomegaly[MeSH Terms] OR Hypertrophy, Left Ventricular[MeSH Terms] OR Cardiomyopathy, Dilated[MeSH Terms] OR diabetic cardiomyopathy[MeSH Terms]) AND

(diabetes[MeSH Major Topic] OR prediabetes[MeSH Terms] OR hyperglycemia[MeSH Terms] OR insulin resistance[MeSH Terms] OR streptozotocin[All Fields]

OR alloxan[All Fields] OR Dithizone[All Fields] OR 8-hydroxyquinolone[All Fields] OR spontaneously diabetic[All Fields] OR db/db[All Fields] OR diabetic mouse[All Fields] OR diabetic mice[All Fields] OR diabetic rat*[All Fields] OR non-obese diabetic[tw] OR biobreeding rat[All Fields]) AND

(fetal gene[tw] OR fetal gene program[tw] OR myosin heavy chain[tw] OR N2BA*[tw] OR GATA4[tw] OR NFAT[tw] OR (Csx[tw] OR NKX*[tw]) OR SRF[tw] OR MEF2[tw] OR Hand1/2[tw] OR Smad[tw] OR ANP[tw] OR ANF[tw] OR atrial natriuretic peptide[tw] OR atrial natriuretic factor[tw] OR BNP[tw] OR BNF[tw] OR brain natriuretic peptide[tw] OR brain natriuretic factor[tw] OR alpha skeletal actin[tw] OR skeletal actin[tw] OR alpha actin[tw] OR SERCA*[tw]) AND

Journal Article[PT] AND

(cardiomyocyte[MeSH Terms] OR primary cell*[MeSH Terms] OR ventricular myocyte[tw] OR models, animal[MeSH Terms] OR mouse heart*[MeSH Terms] OR rat heart*[MeSH Terms]) AND

1980:2013[dp]

doi:10.1371/journal.pone.0092903.t001

\section{Statistics}

Specific effect sizes were not reported for most studies; therefore, we categorized changes as up (1), down $(-1)$, or no change (0), and used non-parametric Mann-Whitney, Chisquared, and Spearman regression analyses as appropriate. Significance was set at $\mathrm{P}<0.05$.

\section{Results}

General description of methods/animal characteristics

Overall, 38 studies (33\% of this database) used T2DM models while 78 studies $(67 \%)$ used TIDM models. By far the most commonly used T1DM model was the Sprague-Dawley rat induced with STZ (TABLE 2). The most commonly used model of T2DM was the $d b / d b$ mouse. Only one study used alloxan as their diabetogenic [55] and no studies used dithizone or 8hydroxyquinolone. Therefore, as alloxan and STZ have very similar mechanisms of action, we grouped these drugs together into a single category of drug-induced diabetes for statistical analyses.

Dose reporting varied for the studies that used STZ or alloxan. Single-dose STZ was the most common method ( $\mathrm{n}=58$ ); however, the number of doses varied from two to seven (TABLE 3). Two studies did not report the number of doses of the diabetogenic agent.

One study used both male and female C57BL/6 mice for their project [56], 16 used female mice and rats, and 96 used male mice and rats. Ninety-six studies reported either a starting age or weight. Twenty studies did not report the age of their experimental animals. Thirty-three did not report the change in body weight of their animals (i.e. wasting, fat, or no change) after diabetogenic intervention.

Heart weight (HW) was the most frequent method of reporting cardiac hypertrophy (TABLE 4). The most common indexing method was normalization to body weight; few studies reported the HW:tibia length (TL) index. Although 33 studies did not report total body weight, seven of these 33 studies reported the HW:BW or HW:TL index.

\section{The type of diabetes/diabetogenic moderates hypertrophy}

Neither the age of animals at sacrifice (stratified in 5-week increments) or animal sex had any effect on absolute final heart weight. Rodent species did not affect absolute final HW; however, diabetic rats were significantly more likely to show an increase in
HW:BW compared to diabetic mice $(\mathrm{P}<0.05)$. This finding may be confounded by the fact that diabetic rats were significantly more likely to show loss of body weight compared to diabetic mice $(\mathrm{P}<0.05)$.

The difference in absolute heart weight from controls was significantly lower in T1DM models than T2DM models $(\mathrm{P}<0.05)$ (FIGURE 2). The type of diabetes had no significant effect on HW:BW, left ventricular weight:body weight, cardiomyocyte area, or the presence of cardiac dysfunction. The category of

Table 2. Descriptive summary of rodent models of experimental diabetes.

\begin{tabular}{|c|c|c|c|c|}
\hline Drug & Strain & Species & $\mathbf{N}$ & $\begin{array}{l}\text { Diabetes } \\
\text { type }\end{array}$ \\
\hline Alloxan & Sprague-Dawley & Rat & 1 & T1DM \\
\hline Spontaneous & Akita & Mouse & 3 & T1DM \\
\hline STZ & Sprague-Dawley & Rat & 33 & T1DM \\
\hline $\mathrm{STZ}$ & Wistar & Rat & 16 & T1DM \\
\hline $\mathrm{STZ}$ & $\mathrm{C} 57 \mathrm{BL} / 6$ & Mouse & 15 & T1DM \\
\hline STZ & FVB & Mouse & 4 & T1DM \\
\hline STZ & Wistar-Kyoto & Rat & 2 & T1DM \\
\hline STZ & - & - & 2 & T1DM \\
\hline STZ & CR1:W1 & Rat & 1 & T1DM \\
\hline STZ & CD1 & Mouse & 1 & T1DM \\
\hline Combination (Diet + STZ) & Wistar & Rat & 2 & T2DM \\
\hline Combination (Diet + STZ) & Sprague-Dawley & Rat & 1 & T2DM \\
\hline Diet & Wistar & Rat & 2 & T2DM \\
\hline Diet & Sprague-Dawley & Rat & 1 & T2DM \\
\hline Diet & $\mathrm{C} 57 \mathrm{BL} / 6$ & Mouse & 1 & T2DM \\
\hline Spontaneous & $\mathrm{db} / \mathrm{db}$ & Mouse & 14 & T2DM \\
\hline Spontaneous & ZDF & Rat & 5 & T2DM \\
\hline Spontaneous & Goto-Kakizaki & Rat & 4 & T2DM \\
\hline Spontaneous & OLETF & Rat & 3 & T2DM \\
\hline Spontaneous & NOD & Mouse & 2 & T2DM \\
\hline Spontaneous & UCD-T2DM & Rat & 1 & T2DM \\
\hline Spontaneous & OVE26 & Mouse & 1 & T2DM \\
\hline Spontaneous & $\mathrm{ob} / \mathrm{ob}$ & Mouse & 1 & T2DM \\
\hline
\end{tabular}


Table 3. Summary of dosing regimens used to induce experimental diabetes in rodents.

\begin{tabular}{|c|c|c|c|c|c|c|}
\hline Species & Strain & Sex & Diabetogenic & Doses & $\mathbf{N}$ & Diabetes type \\
\hline Mouse & C57BL/6 & M & STZ & 1 & 5 & T1DM \\
\hline Mouse & C57BL/6 & M & STZ & 2 & 1 & T1DM \\
\hline Mouse & C57BL/6 & M & STZ & 3 & 3 & T1DM \\
\hline Mouse & C57BL/6 & M & STZ & 5 & 3 & T1DM \\
\hline Mouse & C57BL/6 & M & STZ & 7 & 2 & T1DM \\
\hline Mouse & C57BL/6 & $\mathrm{M}$ and $\mathrm{F}$ & STZ & 7 & 1 & T1DM \\
\hline Mouse & CD1 & M & STZ & 1 & 1 & T1DM \\
\hline Mouse & FVB & M & STZ & 1 & 1 & T1DM \\
\hline Mouse & FVB & M & STZ & 5 & 3 & T1DM \\
\hline Rat & CR1:W1 & Not reported & STZ & 1 & 1 & T1DM \\
\hline Rat & Not reported & $\mathrm{F}$ & STZ & 1 & 1 & T1DM \\
\hline Rat & Not reported & M & STZ & 1 & 1 & T1DM \\
\hline Rat & Sprague-Dawley & $\mathrm{F}$ & STZ & 1 & 5 & T1DM \\
\hline Rat & Sprague-Dawley & $\mathrm{F}$ & STZ & 3 & 1 & T1DM \\
\hline Rat & Sprague-Dawley & M & alloxan & 1 & 1 & T1DM \\
\hline Rat & Sprague-Dawley & M & STZ & 1 & 26 & T1DM \\
\hline Rat & Sprague-Dawley & Not reported & STZ & 1 & 1 & T1DM \\
\hline Rat & Wistar & M & STZ & 1 & 14 & T1DM \\
\hline Rat & Wistar & M & STZ & Not reported & 2 & T1DM \\
\hline Rat & Wistar-Kyoto & M & STZ & 1 & 2 & T1DM \\
\hline Rat & Sprague-Dawley & $\mathrm{F}$ & High fructose diet + STZ & 1 & 1 & $\mathrm{~T} 2 \mathrm{DM}$ \\
\hline Rat & Wistar & M & High fructose/high sugar diet + STZ & 1 & 2 & T2DM \\
\hline
\end{tabular}

diabetogenic agent (drug vs. spontaneous vs. other) had similar effects on hypertrophy. Diabetogenic category significantly influenced absolute heart weight $(\mathrm{P}<0.05)$, but had no significant effect on HW:BW or HW:TL.

Because the HW:BW ratio was the most common method of indexing, we also investigated the effects of diabetes type and diabetogenic on body weight (FIGURE 3). T1DM animals showed significant loss of body weight relative to T2DM animals $(\mathrm{P}<0.05)$. Drug-induced diabetic animals also showed significant

Table 4. Frequency of methods used to report cardiac hypertrophy.

\begin{tabular}{ll}
\hline & $\mathbf{N}$ \\
\hline Measure & 48 \\
\hline HW & 43 \\
HW:BW & 8 \\
LVW:BW & 8 \\
Cardiomyocyte area & 7 \\
HW:TL & 7 \\
LVW & 1 \\
RVW & 1 \\
RVW:BW & \\
\hline Measure indicates the value or index used to report cardiac hypertrophy. N \\
indicates the number of studies that reported that measure. HW = heart weight; \\
BW = body weight; TL=tibia length; LVW= left ventricle weight; RVW = right \\
$\begin{array}{l}\text { ventricle weight. } \\
\text { doi:10.1371/journal.pone.0092903.t004 }\end{array}$
\end{tabular}

loss of body weight compared to spontaneous- or diet/druginduced models of diabetes $(\mathrm{P}<0.05)$.

The effect of diabetes duration on cardiac hypertrophy

We coded the duration of diabetes as the time from the final drug administration to the time the animals were sacrificed (for drug-induced diabetes), or as the amount of time a diet was consumed (for diet-induced diabetes). We then stratified the time of the intervention in 5-week increments ranging from 0 to $>20$ weeks. The HW and the HW:BW index were not affected by rodent age at the start of the intervention, rodent age at the time of analysis, or the duration of the diabetogenic intervention.

There were not sufficient data in each 5-week increment to compare effects of time on fetal genes. Therefore, we recategorized the shortest duration of diabetes $(0-5$ weeks $)$ as "acute" and pooled the longer durations as "chronic" (range: 5.132 weeks). Acute vs. chronic diabetes had no effect on absolute final heart weight, or body weight. However, increased HW:BW was significantly more common in chronic models than acute models. Acute vs. chronic diabetes had no effect on any fetal gene protein or mRNA levels.

Since some studies used multiple rather than single STZ dosing, we controlled for effects of dose, and interactions of dose by duration of diabetes. Dose number (ranging from 1-7) had no effect on HW or the HW:BW index. There were not a sufficient number of studies in each dose category to compare the effect of dose on fetal gene protein or mRNA levels. 

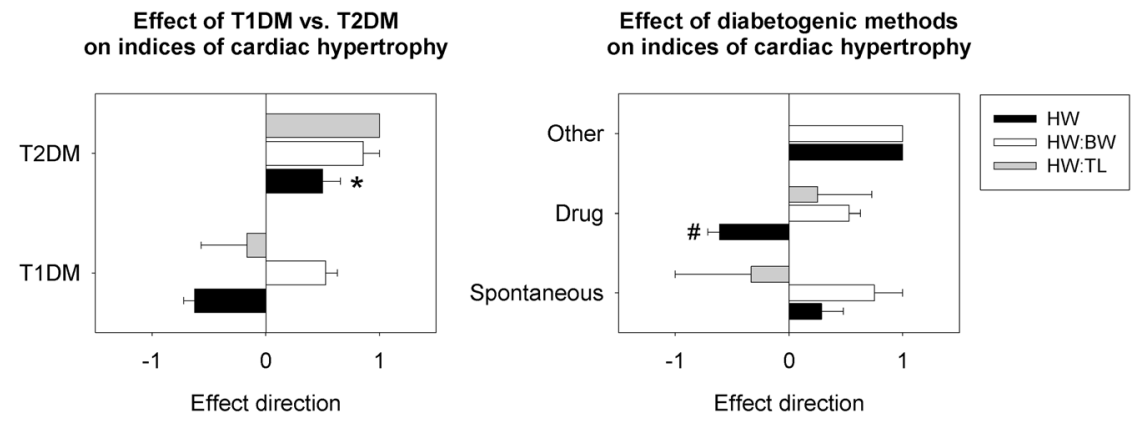

Figure 2. Effect of diabetes type and methods of diabetogenicity on indices of cardiac hypertrophy in experimental rodent models of diabetes. The type of diabetes and the method of inducing diabetes significantly affect absolute heart weight but not the HW:BW index in rodent models of diabetes. * significant effect of diabetes type; \# significant effect of diabetogenic from both other categories. Significance set at $\mathrm{P}<0.05$. T1DM = type 1 diabetes mellitus; T2DM = type 2 diabetes mellitus; HW = heart weight; $\mathrm{BW}=$ body weight; $\mathrm{TL}=$ tibia length.

doi:10.1371/journal.pone.0092903.g002

\section{Fetal genes are not correlated with HW:BW or other fetal genes}

Serca2. Neither the diabetogenic category nor the diabetes type had any significant effect on Serca2 protein or mRNA levels. Overall, diabetic animals consistently showed lower Serca2 protein levels relative to non-diabetic controls (FIGURE 4). There was no significant effect of species (mouse vs. rat) on Serca2 expression, and no interaction of species with diabetogenic method.

Myofilament isoforms. The type of diabetes had no effect on $\alpha$-MHC protein or mRNA levels. However, the type of diabetes moderated the expression of $\beta$-MHC. Although protein and transcript levels of $\beta$-MHC were upregulated in diabetic animals relative to controls overall, the extent of this upregulation was significantly greater in the T1DM group compared to the T2DM group $(\mathrm{P}<0.05)$ (FIGURE 5).

Protein and mRNA levels of $\alpha-\mathrm{MHC}$ and protein levels of $\beta$ MHC were not different between diabetogenic groups. mRNA levels of $\beta$-MHC were significantly higher in the drug-induced diabetogenic category compared to the spontaneous diabetogenic category $(\mathrm{P}<0.05)$. Interestingly, rodent species (mouse vs. rat) had a significant effect on $\beta$-MHC mRNA levels; rats more frequently showed an increase in $\beta$-MHC mRNA compared to mouse models $(\mathrm{P}<0.05)$, but there was no significant interaction of species with diabetogenic method.
There were not sufficient data to compare the $\alpha$-MHC/ $\beta$-MHC ratio between groups, and the small numbers of studies in our dataset showed conflicting results. The ratio decreased in a spontaneous rat model of T2DM [21] and in a rat model of STZinduced TIDM [57]. However, it increased in the hearts of female type 2 diabetic $d b / d b$ mice [12].

Natriuretic peptides. Animal models of T1DM tended to show higher transcript levels of ANP relative to controls than T2DM models $(\mathrm{P}=0.057)$ (FIGURE 6). The diabetogenic category did not have any effect on ANP protein levels; however, drug-induced models also tended to show higher ANP transcript levels relative to spontaneous models $(\mathrm{P}=0.057)$. Diabetogenic category did not have any effect on BNP mRNA, and there were not sufficient data to compare BNP protein levels between diabetogenic categories. However, our dataset included three studies that showed increased BNP protein levels in the hearts of type 1 diabetic Akita mice [58], type 1 diabetic STZ-induced diabetic FVB mice [59], and UC Davis type 2 diabetic rats [60]. There was no significant effect of species (mouse vs. rat) on natriuretic peptide expression, and no interaction of species with diabetogenic method.

Correlations of fetal genes with cardiac hypertrophy. Spearman regression was performed to correlate fetal gene mRNA and protein levels with absolute heart weight and the HW:BW index. We report correlations for which $\mathrm{N} \geq 3$ studies.
Effect of T1DM vs. T2DM on body mass

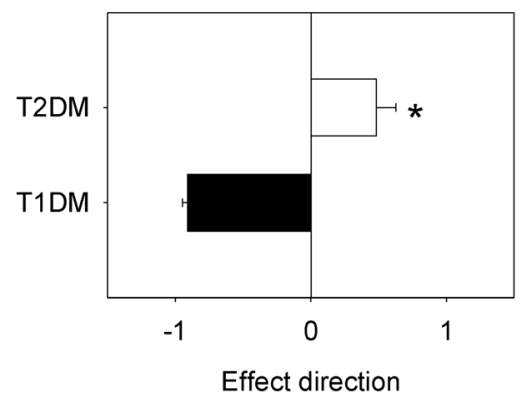

Effect of diabetogenic methods on body mass

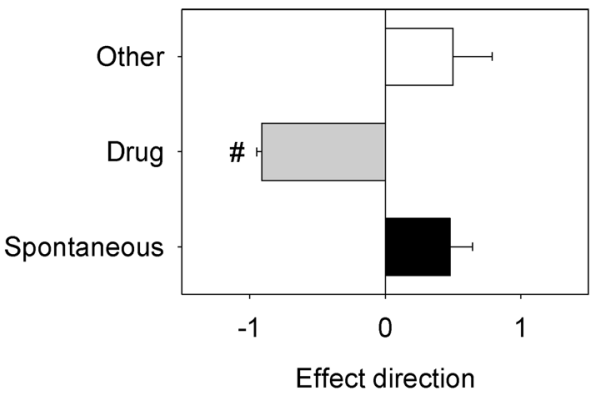

Figure 3. Effect of diabetes type and methods of diabetogenicity on body weight in experimental rodent models of diabetes. The type of diabetes and the method of inducing diabetes significantly affect final body weight in rodent models of diabetes. ${ }^{*}$ significant effect of diabetes type; \# significant effect of diabetogenic from both other categories. Significance set at P $<0.05$. T1DM = type 1 diabetes mellitus; $\mathrm{T} 2 \mathrm{DM}=$ type 2 diabetes mellitus.

doi:10.1371/journal.pone.0092903.g003 

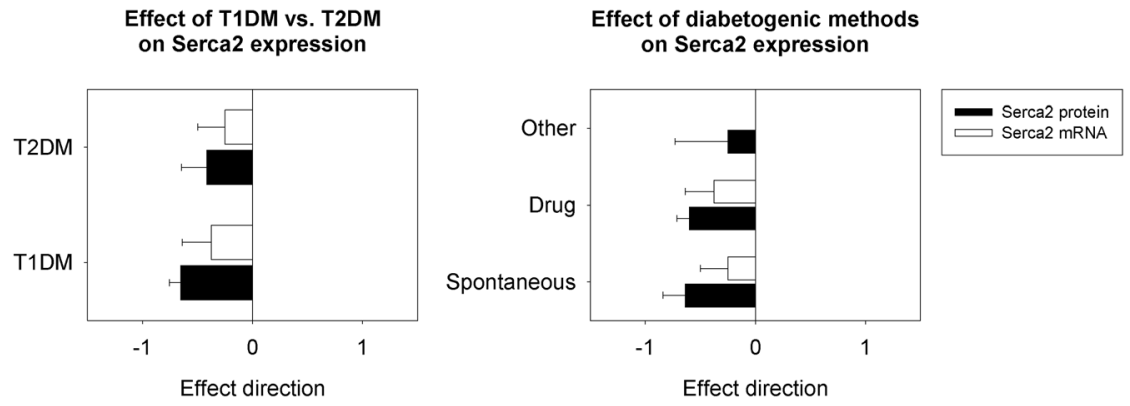

Figure 4. Effect of diabetes type and methods of diabetogenicity on cardiac Serca2 expression. Serca2 is not affected by either diabetes type or by different methods of inducing diabetes in the hearts of experimental rodent models of diabetes. T1DM = type 1 diabetes mellitus; T2DM = type 2 diabetes mellitus.

doi:10.1371/journal.pone.0092903.g004

ANP protein levels were negatively correlated with absolute heart weight $(\mathrm{P}<0.05)$, but mRNA levels of ANP were not associated with heart weight (TABLE 5). Similarly, $\alpha$-MHC protein was directly correlated with increases in absolute heart weight $(\mathrm{P}<0.05)$, but transcript levels of $\alpha$-MHC were not.

The HW:BW index did not correlate with the expression of any fetal genes (TABLE 6). There were not enough data to correlate fetal genes with the HW:TL index, as only seven studies reported this index.

We then examined these correlations separately within type 1 and type 2 diabetes models. In T1DM models, no fetal genes correlated with heart weight or the HW:BW index (TABLE 7, 8). However, in T2DM models, BNP mRNA levels were directly correlated to absolute heart weight $(\mathrm{P}<0.05)$ (TABLE 9), although protein levels of BNP were not.

Correlations of fetal genes with each other. In the 12 studies that measured both ANP and BNP, ANP protein correlated with BNP mRNA $(\mathrm{P}<0.05)$. The eight studies that measured Serca2 protein and Serca2 mRNA showed a direct correlation between these two $(\mathrm{P}<0.05)$. Finally, in nine studies $\alpha-$ MHC protein was negatively correlated with $\beta$-MHC protein $(\mathrm{P}<0.05)$. However, there were no correlations between fetal genes in different categories: the expression of fetal myofilaments did not correlate with Serca2 or the natriuretic peptides, and vice versa.

\section{Miscellaneous results}

Several of our search terms returned too few studies for statistical analysis; these results are summarized below.
Transcription factors. Two studies showed that NCX levels decreased in the hearts of STZ-induced diabetic rats [61,62]. However, cardiac NCX protein was unchanged in another study with STZ-induced diabetic rats [63], and was increased in the Akita mouse [64]. One study showed that cardiac MEF2 was reduced in STZ-induced diabetic rats [57], but another study showed an increase [65]. Cardiac mRNA levels of MEF2 were increased in STZ-induced diabetic mice [66]. E-hand and D-hand protein levels were decreased in the hearts of STZ-induced rats [57], but did not change in another study with STZ-induced diabetic rats [65].

Both SMAD2 [67] and SMAD7 [68] protein levels were increased in STZ-induced diabetic rat hearts. Cardiac phosphoSMAD2 and phospho-SMAD3 were also increased in highfructose-fed diabetic rats [69] and STZ-induced diabetic rats [70]. One study found an increase in phosphorylated GATA4 in STZinduced diabetic rat hearts [71].

Cardiac $\boldsymbol{\alpha}$-actin. Cardiac $\boldsymbol{\alpha}$-actin is the form of actin expressed in the postnatal and adult heart; downregulation of cardiac $\alpha$-actin is indicative of fetal gene activation in cardiomyocytes. In our database, one study showed that transcript levels of cardiac $\alpha$-actin did not change in STZ-induced rats [14]. Two studies showed that cardiac $\alpha$-actin was reduced in STZ-induced diabetic rats [72] and $d b / d b$ type 2 diabetic mice [73].

Natriuretic peptides. One study showed that ANP protein was reduced in the atria but increased in the ventricles of STZinduced diabetic rats [74]. Insulin normalized an increase in leftventricular transcript levels of ANP in STZ-induced diabetic rats in one study [15]. Both plasma ANP and granular ANP within
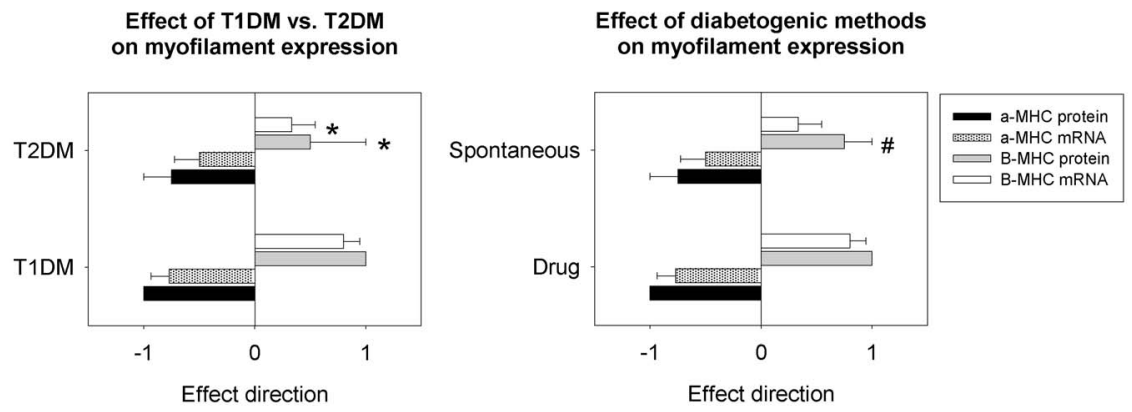

Figure 5. Effect of diabetes type and methods of diabetogenicity on cardiac myosin expression. The type of diabetes and the method of inducing diabetes significantly affect the expression of myosins in the hearts of experimental rodent models of diabetes. ${ }^{*}$ significant effect of diabetes type; \# significant effect of diabetogenic category. Significance set at P $<0.05$. T1DM = type 1 diabetes mellitus; T2DM = type 2 diabetes mellitus.

doi:10.1371/journal.pone.0092903.g005 

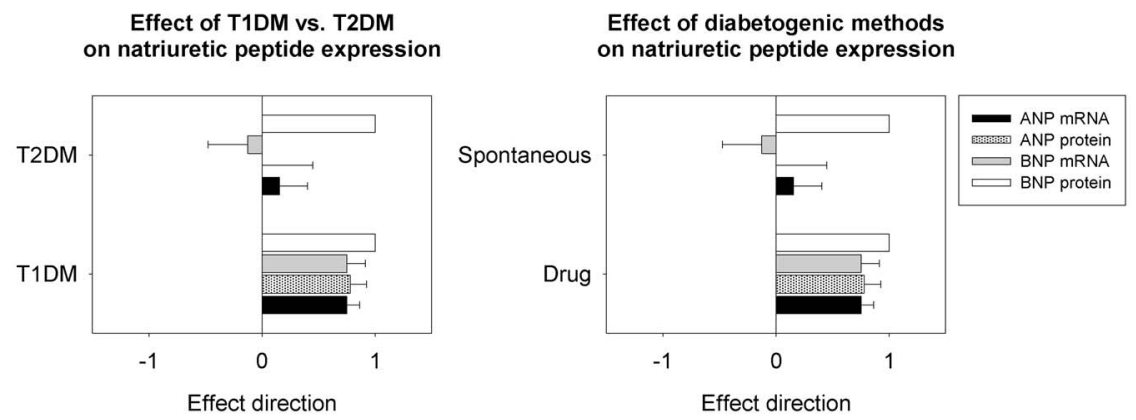

Figure 6. Effect of diabetes type and methods of diabetogenicity on cardiac natriuretic peptide expression. The type of diabetes and the method of inducing diabetes significantly affect the expression of natriuretic peptides in the hearts of experimental rodent models of diabetes. T1DM = type 1 diabetes mellitus; T2DM = type 2 diabetes mellitus. doi:10.1371/journal.pone.0092903.g006

cardiomyocytes were increased in high-fructose fed C57BL/6 mice [75]. Finally, the mRNA levels of the natriuretic peptide receptors NPR-A and NPR-B were increased in STZ-induced C57BL/6 mouse hearts [76].

\section{Discussion}

Results of this study show that diabetogenic methods affect the development of cardiac hypertrophy in diabetic animals, and the expression of fetal genes. Models of T2DM showed cardiac hypertrophy relative to controls, while models of T1DM showed significant loss of heart weight. None of the cardiac fetal genes analyzed in this study correlated with the HW:BW index, the most commonly reported estimate of cardiac hypertrophy. The only members of the FGP that were associated with absolute heart weight were $\alpha$-MHC protein and ANP protein, which had significant positive and negative correlations with heart weight, respectively. However, the mRNA levels of $\alpha-\mathrm{MHC}$ and ANP did not correlate with heart weight. When we separated this analysis by the type of diabetes, BNP mRNA levels were significantly positively correlated with heart weight in type 2 models. Results of this analysis suggest that fetal genes are not generally correlates of cardiac hypertrophy in animal models of diabetes, and that fetal gene expression is confounded by animal species, the type of diabetes (type 1 vs. type 2), and the method of inducing experimental diabetes.

Table 5. Spearman correlations of fetal genes with absolute heart weight.

\begin{tabular}{lllll}
\hline & & & & \\
\hline Correlate & $\boldsymbol{\rho}$ & $\mathbf{P}$ & $\mathbf{N}$ & $\mathbf{P}<\mathbf{0 . 0 5}$ \\
\hline ANP protein & -0.730 & 0.03 & 8 & $*$ \\
ANP mRNA & -0.003 & 0.99 & 15 & NS \\
BNP mRNA & 0.354 & 0.27 & 11 & NS \\
Serca2 protein & 0.170 & 0.60 & 11 & NS \\
Serca2 mRNA & -0.411 & 0.23 & 10 & NS \\
$\alpha-$ MHC protein & 1.000 & 0.02 & 5 & $*$ \\
$\alpha-M H C$ mRNA & 0.362 & 0.29 & 10 & NS \\
$\beta-$ MHC protein & -1.000 & 0.08 & 4 & NS \\
$\beta-M H C$ mRNA & -0.501 & 0.09 & 12 & NS \\
\hline $\begin{array}{l}\text { Spearman correlation coefficients; } \rho=\text { correlation coefficient, P }=p \text { value, N }=\# \\
\text { studies. } \\
\text { doi:10.1371/journal.pone.0092903.t005 }\end{array}$ & & &
\end{tabular}

We also analyzed the correlations of fetal genes with each other to determine whether they showed similar patterns of expression. Interestingly, there were absolutely no correlations in the expression of fetal genes from different functional categories. The expression of genes with similar functions showed some agreement: for example, ANP protein was directly correlated with BNP mRNA levels, Serca2 mRNA and protein levels correlated with each other, and levels of $\alpha-\mathrm{MHC}$ and $\beta$-MHC protein were negatively correlated. These data suggest that fetal genes within similar functional categories, e.g. the natriuretic peptides or the heavy chain myosins, may be co-regulated in diabetic hearts. However, the natriuretic peptides did not correlate with Serca2 or the myosins, and vice versa. Collectively, these findings do not support the concept of a cohesively regulated FGP in the diabetic heart.

Most studies reported that cardiac expression of $\beta$-MHC was increased in experimental diabetic animals relative to controls. However, this was significantly moderated by the type of diabetes: type 1 animals consistently showed greater upregulation of $\beta$ MHC protein and mRNA than type 2 models. $\beta$-MHC was also not associated with cardiac hypertrophy in our correlation analysis. Surprisingly, the expression of $\beta-\mathrm{MHC}$ mRNA was significantly higher in rats compared to mice. These results suggest that changes in fetal myofilament isoforms in the adult heart do not strictly indicate cardiac hypertrophy, and are confounded by animal species. It has already been proposed, for example, that $\beta$ MHC is a more specific marker of fibrosis than hypertrophy [77].

Table 6. Spearman correlations of fetal genes with the HW:BW index.

\begin{tabular}{lllll}
\hline Correlate & $\boldsymbol{\rho}$ & $\mathbf{P}$ & $\mathbf{N}$ & $\mathbf{P}<\mathbf{0 . 0 5}$ \\
\hline ANP protein & 0.408 & 0.45 & 5 & NS \\
ANP mRNA & 0.000 & 0.98 & 9 & NS \\
BNP mRNA & 0.612 & 0.23 & 5 & NS \\
Serca2 protein & 0.234 & 0.39 & 15 & NS \\
Serca2 mRNA & 0.310 & 0.56 & 6 & NS \\
$\alpha-M H C$ protein & -0.250 & 0.68 & 5 & NS \\
$\alpha-M H C$ mRNA & 0.452 & 0.23 & 8 & NS \\
$\beta$-MHC mRNA & -0.186 & 0.58 & 10 & NS \\
\hline $\begin{array}{l}\text { Spearman correlation coefficients; } \rho=\text { correlation coefficient, } P=p \text { value, N = \# } \\
\text { studies. } \\
\text { doi:10.1371/journal.pone.0092903.t006 }\end{array}$ & & &
\end{tabular}


Table 7. Spearman correlations of fetal genes with absolute heart weight in rodent models of type 1 diabetes.

\begin{tabular}{lllll}
\hline Correlate & $\boldsymbol{\rho}$ & $\mathbf{P}$ & $\mathbf{N}$ & $\mathbf{P}<0.05$ \\
\hline ANP protein & -0.707 & 0.14 & 6 & NS \\
ANP mRNA & -0.167 & 0.66 & 7 & NS \\
BNP mRNA & -0.577 & 0.42 & 4 & NS \\
Serca2 protein & -0.250 & 0.49 & 9 & NS \\
Serca2 mRNA & -0.816 & 0.08 & 4 & NS \\
$\alpha-$ MHC protein & 1.000 & 0.08 & 4 & NS \\
$\alpha-M H C$ mRNA & 0.632 & 0.18 & 6 & NS \\
$\beta-M H C$ protein & 1.000 & 0.33 & 3 & NS \\
$\beta-M H C$ mRNA & -0.571 & 0.12 & 8 & NS \\
\hline $\begin{array}{l}\text { Spearman correlation coefficients; } \rho=\text { correlation coefficient, } \mathrm{P}=\mathrm{p} \text { value, N = \# } \\
\text { studies. } \\
\text { doi:10.1371/journal.pone.0092903.t007 }\end{array}$ & & &
\end{tabular}

However, this does not explain the discordant results we found regarding the $\alpha$-MHC/ $\beta$-MHC ratio in diabetic hearts. Studies reported that this ratio decreased in spontaneously type 2 diabetic rats [21] and in STZ-induced type 1 diabetic rats [57], but increased $\mathrm{n}$ the hearts of female type 2 diabetic $d b / d b$ mice [12].

\section{Hypertrophic phenotyping methods}

We found that methods of reporting hypertrophy significantly influence the interpretation of the cardiac phenotype. Absolute heart weight was the most common method of reporting hypertrophy, followed by the HW:BW index. Only seven studies reported the HW:TL index, which is a more reliable correlate of cardiomyocyte area than either HW or HW:BW [78]. Importantly, according to the HW:BW index, there were no significant differences in hypertrophy between animal models of diabetes, and all animals showed hypertrophy. However, both absolute heart weight and body weight were significantly different between type 1 and type 2 animals: type 1 animals generally showed cachexia and a loss of heart weight, and type 2 models showed obesity and an increase in heart weight. We found that seven studies did not report body weight and only reported either the HW:BW or HW:TL ratio. Until more is understood about hypertrophy in various animal models of diabetes, we suggest that studies report multiple indices of hypertrophy, because the results of this analysis show that simple indexing methods can mask important phenotypic differences.

\section{Diabetogenic methods}

We propose that the use of toxic glucose analogues for inducing diabetes, which is one of the most common methods for studying diabetic cardiomyopathy at the present time, should be reexamined. At high doses, these diabetogenics induce a model of T1DM that develops cardiac atrophy, cachexia, and primary insulin deficiency. This is a clear departure from the phenotype of humans who develop diabetic cardiomyopathy secondary to T2DM, who are typically hyperinsulinemic, obese, insulin resistant, and show cardiac hypertrophy. The incidence of human diabetes is also overwhelmingly type 2 (approximately 95\% of all diabetics); therefore, models of primary insulin deficiency induced with toxic glucose analogues have limited application to the clinical entity of diabetic cardiomyopathy.

These diabetogenic agents also may be toxic to multiple organs and have independent effects on cardiac function. The mechanism
Table 8. Spearman correlations of fetal genes with the HW:BW index in rodent models of type 1 diabetes.

\begin{tabular}{lllll}
\hline Correlate & $\boldsymbol{\rho}$ & $\mathbf{P}$ & $\mathbf{N}$ & $\mathbf{P}<\mathbf{0 . 0 5}$ \\
\hline ANP protein & 0.408 & 0.45 & 5 & NS \\
ANP mRNA & 0.123 & 0.75 & 8 & NS \\
BNP mRNA & 0.500 & 1.00 & 3 & NS \\
Serca2 protein & 0.200 & 0.51 & 12 & NS \\
Serca2 mRNA & 0.395 & 0.52 & 5 & NS \\
$\alpha-M H C$ mRNA & 0.452 & 0.23 & 8 & NS \\
$\beta-M H C$ protein & 1.000 & 0.33 & 3 & NS \\
$\beta-$ MHC mRNA & -0.186 & 0.58 & 10 & NS \\
\hline
\end{tabular}

Spearman correlation coefficients; $\rho=$ correlation coefficient, $P=p$ value, $N=\#$ studies.

doi:10.1371/journal.pone.0092903.t008

of action of STZ and alloxan is inducing cell death secondary to alkylating and oxidative DNA damage, and disruption in calcium kinetics [79]. Other mechanisms of $\beta$-cell toxicity include inhibition of $\mathrm{O}$-linked $\beta-\mathrm{N}$-acetylglucosaminidase, which removes O-linked $\beta$-N-acetylglucosamine (O-GlcNAc) groups from serine/ threonine residues of proteins [80]. This toxicity is relatively selective to pancreatic $\beta$-cells; however, animals treated with alloxan or STZ also exhibit hepatoxocity and signs of kidney damage [81]. STZ also independently reduces cardiomyocyte contractility [82] and both alloxan and STZ induce cardiomyocyte dysfunction [83,84].

Many hypotheses have been proposed for the dysfunctional phenotype of the diabetic heart, including disruption in calcium kinetics, increased oxidative stress, energetic disturbances due to glucotoxicity and/or lipotoxicity, inflammation, and cardiomyocyte apoptosis; for recent reviews, see [85] and [86]. It is critical to recognize that the independent effects of toxic glucose analogs on these aspects of cardiomyocyte function that are considered indicative of diabetic cardiomyopathy, such as lipotoxicity and oxidative stress, have simply not been examined. Therefore, the use of toxic glucose analogues may not produce a physiologically relevant model of diabetic cardiomyopathy.

\section{Interpretations and proposed mechanisms}

The basic relationship between cardiac hypertrophy and fetal gene activation is unresolved. Although many excellent reviews have been published on the transcriptional mechanisms that regulate these genes [2,50-52,87], the pathways that activate these mechanisms are very poorly understood. It is also not yet

Table 9. Spearman correlations of fetal genes with absolute heart weight in rodent models of type 2 diabetes.

\begin{tabular}{lllll}
\hline Correlate & & $\mathbf{P}$ & $\mathbf{N}$ & $\mathbf{P}<\mathbf{0 . 0 5}$ \\
\hline ANP mRNA & 0.559 & 0.14 & 8 & NS \\
BNP mRNA & 0.833 & 0.01 & 7 & $*$ \\
Serca2 mRNA & 0.000 & 1.00 & 6 & NS \\
$\alpha-M H C$ mRNA & -0.577 & 0.42 & 4 & NS \\
$\beta-M H C$ mRNA & 0.333 & 0.75 & 4 & NS \\
\hline
\end{tabular}

Spearman correlation coefficients; $\rho=$ correlation coefficient, $P=p$ value, $N=\#$ studies.

doi:10.1371/journal.pone.0092903.t009 
established whether FGP activation is a cause or a result of hypertrophy, or whether it is beneficial or decompensatory. For example, the natriuretic peptides antagonize hypertrophy and fibrosis $[35,88,89]$, suggesting that their action is beneficial. Conversely, the loss of Serca2 expression in lieu of fetal-type calcium handling proteins is clearly detrimental for the adult heart [18,21,62,90-92].

An emerging hypothesis proposes that fetal gene expression in the adult heart represents compensatory dedifferentiation, or fetal "reprogramming," of adult cardiomyocytes. Adult cardiomyocytes show considerable plasticity in their differentiation state [93], and dedifferentiate in response to insults such as myocardial infarction, chronic hypertension, and heart failure [94,95]. However, the underlying mechanisms are not well understood, and cardiomyocyte plasticity may even be intrinsically different between animal strains [96]. Indeed, the ability to revert from an adult phenotype may be an inherently protective process in the adult heart [95], mimicking the highly cardioprotective phenotype of the fetal heart [97]. This has led to speculation that fetal gene activation in pathological hypertrophy is a protective mechanism $[2,50]$ and is supported by evidence that the expression of a fetal transcriptome is highly cardioprotective $[97,98]$. However, this hypothesis does not yet explain why some fetal genes are regulated differently in fetal vs. diseased hearts. For example, it is not well established why the $\mathcal{N} p p a$ gene is reactivated in heart disease [99], and N $p p a$ has distinct regulatory sequences that are activated in the embryonic heart and the adult failing heart [100]. The question is complicated by the fact that the fetal and failing hearts are not the only ones that express fetal genes; an adult heart deprived of afterload also upregulates fetal gene expression [101].

It is also possible that the expression of fetal genes is closely tied to myocardial metabolism. This would explain why the presence of simultaneous metabolic disease and cardiac hypertrophy would have confounding effects on fetal gene expression in diabetic hearts. The adult heart upregulates glycolytic metabolism during pathological hypertrophy, and it has been proposed that this shift toward fetal-like myocardial metabolism underlies fetal gene activation and cardiac dysfunction [86,102]. The diabetic heart, by contrast, becomes almost exclusively reliant on fatty acid oxidation [103,104]. Therefore, although the diabetic heart develops pathological hypertrophy, the fundamental metabolic differences between the pathologically hypertrophied and diabetic heart may confound the expression of fetal genes in diabetic hearts.

\section{Limitations}

The specific nature of this systematic review limited the number of results returned by our search parameters. For example, our

\section{References}

1. Kuwahara K (2013) Role of NRSF/REST in the Regulation of Cardiac Gene Expression and Function. Circulation journal: official journal of the Japanese Circulation Society.

2. Taegtmeyer H, Sen S, Vela D (2010) Return to the fetal gene program: a suggested metabolic link to gene expression in the heart. Ann N Y Acad Sci 1188: 191-198.

3. Bell DS (2003) Diabetic cardiomyopathy. Diabetes care 26: 2949-2951.

4. Galderisi M, Anderson KM, Wilson PW, Levy D (1991) Echocardiographic evidence for the existence of a distinct diabetic cardiomyopathy (the Framingham Heart Study). The American journal of cardiology 68: 85-89.

5. Hsu BG, Shih MH, Yang YC, Ho GJ, Lee MC (2012) Fasting long-acting natriuretic peptide correlates inversely with metabolic syndrome in kidney transplant patients. Transplantation proceedings 44: 646-650.

6. Gutkowska J, Broderick TL, Bogdan D, Wang D, Lavoie JM, et al. (2009) Downregulation of oxytocin and natriuretic peptides in diabetes: possible implications in cardiomyopathy. J Physiol 587: 4725-4736. database did not return a sufficient number of studies to correlate the expression of fetal genes with HW:TL, since this was an uncommon method of measuring cardiac hypertrophy. There were also not sufficient data to compare the $\alpha$-MHC/ $\beta-\mathrm{MHC}$ ratio between groups, or to compare changes in $\mathrm{BNP}$ protein between drug-induced and spontaneous models of diabetes. Therefore, the specific nature of our search parameters and the small number of studies it returned limits our conclusions regarding these variables.

The studies we examined also included a wide variety of strains and genetic backgrounds (TABLE 2). While we were able to detect some significant effects of species on the HW:BW ratio, BW, and $\beta$-MHC mRNA, there were not enough studies to compare the effects of strain within species. Therefore, additional studies are needed to determine whether genetic backgrounds influence these parameters in mice and rats.

Finally, we found that chronic models of diabetes were more likely to show increases in HW:BW. Importantly, however, there was no interaction of diabetes duration and the number of doses of toxic glucose analogues. These data suggest that cardiac gene regulation in diabetes is not the same between mice and rats, and that animal models of diabetes show progressive changes in cardiac hypertrophy independent of the dosing regimen.

\section{Conclusions}

In rodent models of diabetes, $\alpha$-MHC protein and ANP protein levels correlate positively and negatively, respectively, with heart weight. The type of diabetes and the method of diabetogenicity independently moderate body weight and cardiac weight, and the expression of $\beta$-MHC. We found absolutely no correlations between fetal genes and the HW:BW index in animal models of diabetes. These findings indicate that fetal genes are not specific markers of hypertrophy in rodent models of diabetes. In addition, this review finds wide variation in current methods of diabetogenicity as well as methods of reporting cardiac hypertrophy. We suggest that studies using experimental rodent models of diabetes report multiple indices of cardiac hypertrophy to improve the quality of research in this field.

\section{Supporting Information}

Table S1 Complete list of references. (DOCX)

\section{Author Contributions}

Conceived and designed the experiments: EJC SAM. Performed the experiments: EJC. Analyzed the data: EJC. Wrote the paper: EJC SAM.

7. Khan AM, Cheng S, Magnusson M, Larson MG, Newton-Cheh C, et al. (2011) Cardiac natriuretic peptides, obesity, and insulin resistance: evidence from two community-based studies. The Journal of clinical endocrinology and metabolism 96: 3242-3249.

8. Bartels ED, Nielsen JM, Bisgaard LS, Goetze JP, Nielsen LB (2010) Decreased expression of natriuretic peptides associated with lipid accumulation in cardiac ventricle of obese mice. Endocrinology 151: 5218-5225

9. Cox EJ, Marsh SA (2013) Exercise and diabetes have opposite effects on the assembly and O-GlcNAc modification of the mSin3A/HDAC1/2 complex in the heart. Cardiovascular diabetology 12: 101.

10. Mifune H, Suzuki S, Honda J, Kobayashi Y, Noda Y, et al. (1992) Atrial natriuretic peptide (ANP): a study of ANP and its mRNA in cardiocytes, and of plasma ANP levels in non-obese diabetic mice. Cell and tissue research 267: 267-272.

11. Gronholm T, Gheng ZJ, Palojoki E, Eriksson A, Backlund T, et al. (2005) Vasopeptidase inhibition has beneficial cardiac effects in spontaneously diabetic Goto-Kakizaki rats. European journal of pharmacology 519: 267-276. 
12. Yue P, Arai T, Terashima M, Sheikh AY, Cao F, et al. (2007) Magnetic resonance imaging of progressive cardiomyopathic changes in the $\mathrm{db} / \mathrm{db}$ mouse. Am J Physiol Heart Circ Physiol 292: H2106-2118.

13. Kaminski KA, Szepietowska B, Bonda T, Kozuch M, Mencel J, et al. (2009) CCN2 protein is an announcing marker for cardiac remodeling following STZinduced moderate hyperglycemia in mice. Pharmacological reports: PR 61: 496-503.

14. Ruzicska E, Foldes G, Lako-Futo Z, Sarman B, Wellmann J, et al. (2004) Cardiac gene expression of natriuretic substances is altered in streptozotocininduced diabetes during angiotensin II-induced pressure overload. Journal of hypertension 22: 1191-1200.

15. Matsubara H, Mori Y, Yamamoto J, Inada M (1990) Diabetes-induced alterations in atrial natriuretic peptide gene expression in Wistar-Kyoto and spontaneously hypertensive rats. Circ Res 67: 803-813.

16. Shah A, Oh YB, Shan G, Song CH, Park BH, et al. (2010) Angiotensin-(1-7) attenuates hyposmolarity-induced ANP secretion via the Na+-K+ pump. Peptides 31: 1779-1785.

17. Marsh SA, Dell'Italia LJ, Chatham JC (2011) Activation of the hexosamine biosynthesis pathway and protein O-GlcNAcylation modulate hypertrophic and cell signaling pathways in cardiomyocytes from diabetic mice. Amino Acids 40: 819-828.

18. Periasamy M, Bhupathy P, Babu GJ (2008) Regulation of sarcoplasmic reticulum $\mathrm{Ca} 2+$ ATPase pump expression and its relevance to cardiac muscle physiology and pathology. Cardiovasc Res 77: 265-273.

19. Maalouf RM, Eid AA, Gorin YC, Block K, Escobar GP, et al. (2012) Nox4derived reactive oxygen species mediate cardiomyocyte injury in early type 1 diabetes. American journal of physiology Cell physiology 302: C597-604.

20. Zhong Y, Ahmed S, Grupp IL, Matlib MA (2001) Altered SR protein expression associated with contractile dysfunction in diabetic rat hearts. Am J Physiol Heart Circ Physiol 281: H1137-1147.

21. Abe T, Ohga Y, Tabayashi N, Kobayashi S, Sakata S, et al. (2002) Left ventricular diastolic dysfunction in type 2 diabetes mellitus model rats. Am J Physiol Heart Circ Physiol 282: H138-148.

22. Sakata S, Lebeche D, Sakata Y, Sakata N, Chemaly ER, et al. (2006) Mechanical and metabolic rescue in a type II diabetes model of cardiomyopathy by targeted gene transfer. Molecular therapy: the journal of the American Society of Gene Therapy 13: 987-996.

23. Gustafson TA, BahlJJ, Markham BE, Roeske WR, Morkin E (1987) Hormonal regulation of myosin heavy chain and alpha-actin gene expression in cultured fetal rat heart myocytes. The Journal of biological chemistry 262: 1331613322.

24. Lyons GE, Schiaffino S, Sassoon D, Barton P, Buckingham M (1990) Developmental regulation of myosin gene expression in mouse cardiac muscle. J Cell Biol 111: 2427-2436.

25. Hui HP, Li XY, Liu XH, Sun S, Lu XC, et al. (2006) [Adeno-associated viral gene transfer of SERCA2a improves heart function in chronic congestive heart failure rats]. Zhonghua xin xue guan bing za zhi 34: 357-362.

26. Reiser PJ, Portman MA, Ning XH, Schomisch Moravec C (2001) Human cardiac myosin heavy chain isoforms in fetal and failing adult atria and ventricles. Am J Physiol Heart Circ Physiol 280: H1814-1820.

27. Miyata S, Minobe W, Bristow MR, Leinwand LA (2000) Myosin heavy chain isoform expression in the failing and nonfailing human heart. Circ Res 86: 386-390.

28. Krenz M, Robbins J (2004) Impact of beta-myosin heavy chain expression on cardiac function during stress. J Am Coll Cardiol 44: 2390-2397.

29. Driesen RB, Verheyen FK, Debie W, Blaauw E, Babiker FA, et al. (2009) Reexpression of alpha skeletal actin as a marker for dedifferentiation in cardiac pathologies. Journal of cellular and molecular medicine 13: 896-908.

30. Ren R, Oakley RH, Cruz-Topete D, Cidlowski JA (2012) Dual role for glucocorticoids in cardiomyocyte hypertrophy and apoptosis. Endocrinology 153: 5346-5360.

31. Opitz CA, Linke WA (2005) Plasticity of cardiac titin/connectin in heart development. Journal of muscle research and cell motility 26: 333-342.

32. Amodio V, Tevy MF, Traina C, Ghosh TK, Capovilla M (2012) Transactivation in Drosophila of human enhancers by human transcription factors involved in congenital heart diseases. Developmental dynamics: an official publication of the American Association of Anatomists 241: 190-199.

33. Dietz JR (2005) Mechanisms of atrial natriuretic peptide secretion from the atrium. Cardiovasc Res 68: 8-17.

34. Zhang YH, Youm JB, Earm YE (2008) Stretch-activated non-selective cation channel: a causal link between mechanical stretch and atrial natriuretic peptide secretion. Progress in biophysics and molecular biology 98: 1-9.

35. Rosenkranz AC, Hood SG, Woods RL, Dusting GJ, Ritchie RH (2003) B-type natriuretic peptide prevents acute hypertrophic responses in the diabetic rat heart: importance of cyclic GMP. Diabetes 52: 2389-2395

36. Franco V, Chen YF, Oparil S, Feng JA, Wang D, et al. (2004) Atrial natriuretic peptide dose-dependently inhibits pressure overload-induced cardiac remodeling. Hypertension 44: 746-750.

37. Wang D, Oparil S, Feng JA, Li P, Perry G, et al. (2003) Effects of pressure overload on extracellular matrix expression in the heart of the atrial natriuretic peptide-null mouse. Hypertension 42: 88-95.

38. Lafontan M, Moro C, Sengenes C, Galitzky J, Crampes F, et al. (2005) An unsuspected metabolic role for atrial natriuretic peptides: the control of lipolysis, lipid mobilization, and systemic nonesterified fatty acids levels in humans. Arteriosclerosis, thrombosis, and vascular biology 25: 2032-2042.

39. Moskowitz IP, Wang J, Peterson MA, Pu WT, Mackinnon AC, et al. (2011) Transcription factor genes Smad4 and Gata4 cooperatively regulate cardiac valve development. [corrected]. Proc Natl Acad Sci U S A 108: 4006-4011.

40. Rivera-Feliciano J, Lee KH, Kong SW, Rajagopal S, Ma Q, et al. (2006) Development of heart valves requires Gata4 expression in endothelial-derived cells. Development 133: 3607-3618.

41. Maitra M, Schluterman MK, Nichols HA, Richardson JA, Lo CW, et al. (2009) Interaction of Gata4 and Gata6 with Tbx5 is critical for normal cardiac development. Developmental biology 326: 368-377.

42. Molkentin JD, Kalvakolanu DV, Markham BE (1994) Transcription factor GATA-4 regulates cardiac muscle-specific expression of the alpha-myosin heavy-chain gene. Mol Cell Biol 14: 4947-4957.

43. Hasegawa K, Lee SJ, Jobe SM, Markham BE, Kitsis RN (1997) cis-Acting sequences that mediate induction of beta-myosin heavy chain gene expression during left ventricular hypertrophy due to aortic constriction. Circulation 96: 3943-3953.

44. Lien CL, Wu C, Mercer B, Webb R, Richardson JA, et al. (1999) Control of early cardiac-specific transcription of Nkx2-5 by a GATA-dependent enhancer. Development 126: 75-84.

45. Komuro I, Izumo S (1993) Csx: a murine homeobox-containing gene specifically expressed in the developing heart. Proc Natl Acad Sci U S A 90: 8145-8149.

46. Gao XR, Tan YZ, Wang HJ (2011) Overexpression of Csx/Nkx2.5 and GATA-4 enhances the efficacy of mesenchymal stem cell transplantation after myocardial infarction. Circulation journal: official journal of the Japanese Circulation Society 75: 2683-2691.

47. Azakie A, Fineman JR, He Y (2006) Myocardial transcription factors are modulated during pathologic cardiac hypertrophy in vivo. The Journal of thoracic and cardiovascular surgery 132: 1262-1271.

48. Morin S, Pozzulo G, Robitaille L, Cross J, Nemer M (2005) MEF2-dependent recruitment of the HAND1 transcription factor results in synergistic activation of target promoters. The Journal of biological chemistry 280: 32272-32278.

49. Thattaliyath BD, Firulli BA, Firulli AB (2002) The basic-helix-loop-helix transcription factor HAND2 directly regulates transcription of the atrial naturetic peptide gene. Journal of molecular and cellular cardiology 34: 13351344.

50. Rajabi M, Kassiotis C, Razeghi P, Taegtmeyer H (2007) Return to the fetal gene program protects the stressed heart: a strong hypothesis. Heart failure reviews 12: 331-343.

51. Kuwahara K, Nishikimi T, Nakao K (2012) Transcriptional regulation of the fetal cardiac gene program. J Pharmacol Sci 119: 198-203.

52. Dirkx E, da Costa Martins PA, De Windt LJ (2013) Regulation of fetal gene expression in heart failure. Biochimica et biophysica acta.

53. Rees DA, Alcolado JC (2005) Animal models of diabetes mellitus. Diabetic medicine: a journal of the British Diabetic Association 22: 359-370

54. Wang Z, Gleichmann H (1998) GLUT2 in pancreatic islets: crucial target molecule in diabetes induced with multiple low doses of streptozotocin in mice. Diabetes 47: 50-56

55. Golfman L, Dixon IM, Takeda N, Chapman D, Dhalla NS (1999) Differential changes in cardiac myofibrillar and sarcoplasmic reticular gene expression in alloxan-induced diabetes. Molecular and cellular biochemistry 200: 15-25.

56. Nielsen LB, Bartels ED, Bollano E (2002) Overexpression of apolipoprotein B in the heart impedes cardiac triglyceride accumulation and development of cardiac dysfunction in diabetic mice. The Journal of biological chemistry 277 : 27014-27020.

57. Aragno M, Mastrocola R, Medana C, Catalano MG, Vercellinatto I, et al. (2006) Oxidative stress-dependent impairment of cardiac-specific transcription factors in experimental diabetes. Endocrinology 147: 5967-5974.

58. Basu R, Oudit GY, Wang X, Zhang L, Ussher JR, et al. (2009) Type 1 diabetic cardiomyopathy in the Akita (Ins2WT/C96Y) mouse model is characterized by lipotoxicity and diastolic dysfunction with preserved systolic function. Am J Physiol Heart Circ Physiol 297: H2096-2108.

59. Ritchie RH, Love JE, Huynh K, Bernardo BC, Henstridge DC, et al. (2012) Enhanced phosphoinositide 3-kinase(p110alpha) activity prevents diabetesinduced cardiomyopathy and superoxide generation in a mouse model of diabetes. Diabetologia 55: 3369-3381.

60. Guglielmino K, Jackson K, Harris TR, Vu V, Dong H, et al. (2012) Pharmacological inhibition of soluble epoxide hydrolase provides cardioprotection in hyperglycemic rats. Am J Physiol Heart Circ Physiol 303: H853-862.

61. Sheikh AQ, Hurley JR, Huang W, Taghian T, Kogan A, et al. (2012) Diabetes alters intracellular calcium transients in cardiac endothelial cells. PloS one 7: e36840.

62. Le Douairon Lahaye S, Gratas-Delamarche A, Malarde L, Zguira S, Vincent S, et al. (2012) Combined insulin treatment and intense exercise training improved basal cardiac function and $\mathrm{Ca}(2+)$-cycling proteins expression in type 1 diabetic rats. Applied physiology, nutrition, and metabolism = Physiologie appliquee, nutrition et metabolisme 37: 53-62.

63. Ligeti L, Szenczi O, Prestia CM, Szabo C, Horvath K, et al. (2006) Altered calcium handling is an early sign of streptozotocin-induced diabetic cardiomyopathy. International journal of molecular medicine 17: 1035-1043.

64. LaRocca TJ, Fabris F, Chen J, Benhayon D, Zhang S, et al. (2012) Na+/Ca2+ exchanger-1 protects against systolic failure in the Akitains 2 model of diabetic 
cardiomyopathy via a CXCR4/NF-kappaB pathway. Am J Physiol Heart Circ Physiol 303: H353-367.

65. Yeih DF, Yeh HI, Hsin HT, Lin LY, Chiang FT, et al. (2009) Dimethylthiourea normalizes velocity-dependent, but not force-dependent, index of ventricular performance in diabetic rats: role of myosin heavy chain isozyme. Am J Physiol Heart Circ Physiol 297: H1411-1420.

66. Feng B, Chen S, George B, Feng Q Chakrabarti S (2010) miR133a regulates cardiomyocyte hypertrophy in diabetes. Diabetes/metabolism research and reviews 26: 40-49.

67. Bupha-Intr T, Oo YW, Wattanapermpool J (2011) Increased myocardial stiffness with maintenance of length-dependent calcium activation by female sex hormones in diabetic rats. Am J Physiol Heart Circ Physiol 300: H16611668.

68. Van Linthout S, Seeland U, Riad A, Eckhardt O, Hohl M, et al. (2008) Reduced MMP-2 activity contributes to cardiac fibrosis in experimental diabetic cardiomyopathy. Basic research in cardiology 103: 319-327.

69. Zhou H, Li YJ, Wang M, Zhang LH, Guo BY, et al. (2011) Involvement of RhoA/ROCK in myocardial fibrosis in a rat model of type 2 diabetes. Acta pharmacologica Sinica 32: 999-1008.

70. Castoldi G, di Gioia CR, Bombardi C, Perego C, Perego L, et al. (2010) Prevention of myocardial fibrosis by $\mathrm{N}$-acetyl-seryl-aspartyl-lysyl-proline in diabetic rats. Clin Sci (Lond) 118: 211-220.

71. Ku PM, Chen LJ, Liang JR, Cheng KC, Li YX, et al. (2011) Molecular role of GATA binding protein 4 (GATA-4) in hyperglycemia-induced reduction of cardiac contractility. Cardiovascular diabetology 10: 57.

72. Ou HC, Tzang BS, Chang MH, Liu CT, Liu HW, et al. (2010) Cardiac contractile dysfunction and apoptosis in streptozotocin-induced diabetic rats are ameliorated by garlic oil supplementation. Journal of agricultural and food chemistry 58: 10347-10355.

73. Essop MF, Chan WA, Hattingh S (2011) Proteomic analysis of mitochondrial proteins in a mouse model of type 2 diabetes. Cardiovascular journal of Africa 22: $175-178$.

74. Wu SQ Kwan CY, Tang F (1998) Streptozotocin-induced diabetes has differential effects on atrial natriuretic peptide synthesis in the rat atrium and ventricle: a study by solution-hybridization-RNase protection assay. Diabetologia 41: 660-665.

75. Costa MV, Fernandes-Santos C, Faria Tda S, Aguila MB, Mandarim-deLacerda CA (2012) Diets rich in saturated fat and/or salt differentially modulate atrial natriuretic peptide and renin expression in C57BL/6 mice. European journal of nutrition 51: 89-96.

76. Christoffersen C, Bartels ED, Nielsen LB (2006) Heart specific up-regulation of genes for B-type and $\mathrm{C}$-type natriuretic peptide receptors in diabetic mice. European journal of clinical investigation 36: 69-75.

77. Pandya K, Kim HS, Smithies O (2006) Fibrosis, not cell size, delineates betamyosin heavy chain reexpression during cardiac hypertrophy and normal aging in vivo. Proc Natl Acad Sci U S A 103: 16864-16869.

78. Yin FC, Spurgeon HA, Rakusan K, Weisfeldt ML, Lakatta EG (1982) Use of tibial length to quantify cardiac hypertrophy: application in the aging rat. The American journal of physiology 243: H941-947.

79. Szkudelski T (2001) The mechanism of alloxan and streptozotocin action in B cells of the rat pancreas. Physiological research/Academia Scientiarum Bohemoslovaca 50: 537-546

80. Konrad RJ, Mikolaenko I, Tolar JF, Liu K, Kudlow JE (2001) The potential mechanism of the diabetogenic action of streptozotocin: inhibition of pancreatic beta-cell O-GlcNAc-selective $\mathrm{N}$-acetyl-beta-D-glucosaminidase. Biochem J 356: 31-41.

81. Lee JH, Yang SH, Oh JM, Lee MG (2010) Pharmacokinetics of drugs in rats with diabetes mellitus induced by alloxan or streptozocin: comparison with those in patients with type I diabetes mellitus. The Journal of pharmacy and pharmacology 62: 1-23.

82. Wold LE, Ren J (2004) Streptozotocin directly impairs cardiac contractile function in isolated ventricular myocytes via a p38 map kinase-dependent oxidative stress mechanism. Biochem Biophys Res Commun 318: 1066-1071.
83. Salem KA, Kosanovic M, Qureshi A, Ljubisavljevic M, Howarth FG (2009) The direct effects of streptozotocin and alloxan on contractile function in rat heart. Pharmacological research: the official journal of the Italian Pharmacological Society 59: 235-241.

84. Howarth FC, Qureshi A, Shahin A, Lukic ML (2005) Effects of single high-dose and multiple low-dose streptozotocin on contraction and intracellular $\mathrm{Ca} 2+$ in ventricular myocytes from diabetes resistant and susceptible rats. Molecular and cellular biochemistry 269: 103-108.

85. Boudina S, Abel ED (2010) Diabetic cardiomyopathy, causes and effects. Reviews in endocrine \& metabolic disorders 11: 31-39.

86. Stanley WC, Recchia FA, Lopaschuk GD (2005) Myocardial substrate metabolism in the normal and failing heart. Physiol Rev 85: 1093-1129.

87. Razeghi P, Young ME, Alcorn JL, Moravec CS, Frazier OH, et al. (2001) Metabolic gene expression in fetal and failing human heart. Circulation 104: 2923-2931.

88. Horio T, Nishikimi T, Yoshihara F, Matsuo H, Takishita S, et al. (2000) Inhibitory regulation of hypertrophy by endogenous atrial natriuretic peptide in cultured cardiac myocytes. Hypertension 35: 19-24.

89. Nishikimi T, Maeda N, Matsuoka H (2006) The role of natriuretic peptides in cardioprotection. Cardiovasc Res 69: 318-328.

90. Ericsson M, Sjaland C, Andersson KB, Sjaastad I, Christensen G, et al. (2010) Exercise training before cardiac-specific Serca2 disruption attenuates the decline in cardiac function in mice. J Appl Physiol 109: 1749-1755.

91. Kralik PM, Ye G, Metreveli NS, Shem X, Epstein PN (2005) Cardiomyocyte dysfunction in models of type 1 and type 2 diabetes. Cardiovascular toxicology 5: 285-292.

92. Miklos Z, Kemecsei P, Biro T, Marincsak R, Toth BI, et al. (2012) Early cardiac dysfunction is rescued by upregulation of SERCA2a pump activity in a rat model of metabolic syndrome. Acta physiologica 205: 381-393.

93. Jopling C, Sleep E, Raya M, Marti M, Raya A, et al. (2010) Zebrafish heart regeneration occurs by cardiomyocyte dedifferentiation and proliferation. Nature 464: 606-609.

94. Rosenblatt-Velin N, Lerch R, Papageorgiou I, Montessuit C (2004) Insulin resistance in adult cardiomyocytes undergoing dedifferentiation: role of GLUT4 expression and translocation. FASEB journal: official publication of the Federation of American Societies for Experimental Biology 18: 872-874.

95. Thijssen VL, Ausma J, Borgers M (2001) Structural remodelling during chronic atrial fibrillation: act of programmed cell survival. Cardiovasc Res 52: 14-24.

96. Kiper C, Grimes B, Van Zant G, Satin J (2013) Mouse strain determines cardiac growth potential. PloS one 8: e70512.

97. Coles JG, Boscarino C, Takahashi M, Grant D, Chang A, et al. (2005) Cardioprotective stress response in the human fetal heart. The Journal of thoracic and cardiovascular surgery 129: 1128-1136.

98. Branco AF, Pereira SL, Moreira AC, Holy J, Sardao VA, et al. (2011) Isoproterenol cytotoxicity is dependent on the differentiation state of the cardiomyoblast H9c2 cell line. Cardiovascular toxicology 11: 191-203.

99. Houweling AC, van Borren MM, Moorman AF, Christoffels VM (2005) Expression and regulation of the atrial natriuretic factor encoding gene Nppa during development and disease. Cardiovasc Res 67: 583-593.

100. Horsthuis T, Houweling AC, Habets PE, de Lange FJ, el Azzouzi H, et al. (2008) Distinct regulation of developmental and heart disease-induced atrial natriuretic factor expression by two separate distal sequences. Circ Res 102: 849-859.

101. Depre C, Shipley GL, Chen W, Han Q Doenst T, et al. (1998) Unloaded heart in vivo replicates fetal gene expression of cardiac hypertrophy. Nature medicine 4: 1269-1275.

102. Kolwicz SC Jr, Tian R (2011) Glucose metabolism and cardiac hypertrophy. Cardiovasc Res 90: 194-201.

103. Stanley WC, Lopaschuk GD, McCormack JG (1997) Regulation of energy substrate metabolism in the diabetic heart. Cardiovasc Res 34: 25-33.

104. Chess DJ, Stanley WC (2008) Role of diet and fuel overabundance in the development and progression of heart failure. Cardiovasc Res 79: 269-278. 